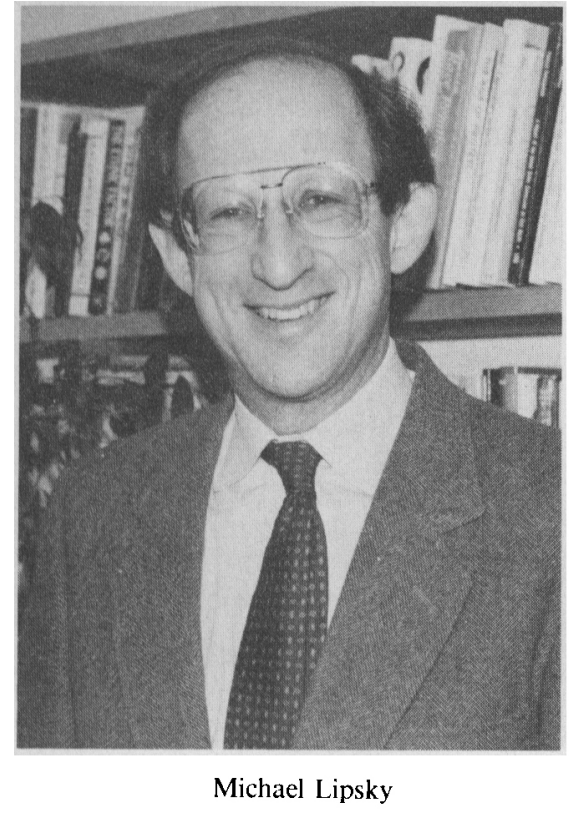

Social Problems, 1981; Guggenheim Fellow, 1984-85.

Publications include Street-Level Bureaucracy: Dilemmas of the Individual in Public Services, 1980; Protest in City Politics: Rent Strikes, Housing and the Power of the Poor, 1970; Commission Politics: The Processing of Racial Crisis in America, 1977.

Fields: Public Policy, Urban and Ethnic Politics.

\section{Lowi Appoints George H. Quester 1991 Program Chair}

APSA President-elect Theodore J. Lowi, Cornell University, has appointed George H. Quester, University of Maryland, 1991 program chair. The 1991 meeting will be held in Washington, D.C. at the Washington Hilton and Towers from August 29 to September 1.

Lowi and Quester have worked together to make sure the overall Program Committee has a certain profile. Specifically, the important criteria include comprehensive coverage of fields, representation of a variety of kinds of institutions throughout all regions of the country, demographic diversity, and inclusion of diverse methodologies and approaches. The program should accommodate the cutting edge of the discipline as well as its mainstream.
There should be many entrances to participate on panels, but not so much so that the Program is unmanageable, incoherent, or unwieldy.

Lowi and Quester adopted a "rule of three" to select the 1991 Program Section Heads. Each Organized Section was asked to nominate three candidates to be Section Head for that Organized Section's field. The Program chair then selected one of the three nominees to be on the 1991 Program Committee, taking into account the criteria described above.

In addition, Lowi and Quester have named other members to the Program Committee to handle parts of the Program not covered by the Organized Sections.

In the 1991 Call For Papers below, the Program section heads appointed through the "rule of three" are indicated with an asterisk (*).

The APSA Council has decided to adopt the "rule of three" method for the next three years, during which it will be closely evaluated.

\section{Call For Papers: 1991 Annual Meeting}

\section{Policies and Deadlines}

Paper proposals and offers to appear as discussants or panel chairpersons must be submitted as early as possible. The deadline for receipt of submissions is December 1, 1990. Proposals for whole panels are welcome, but persons with suggestions for panels should get their requests in early.

Please write directly to the appropriate section Program Committee and/or Organized Section chairperson(s) listed below. More general inquiries or suggestions may be addressed to: George H. Quester, Department of Government and Politics, University of Maryland, College Park, MD 20742-8221, (703) 534-1396; Convention Coordinator, APSA, 1527 New Hampshire Avenue, NW, Washington, DC 20036, (202) 483-2512.

Prospective participants should be aware of two APSA Council policies:

(1) Acceptance of a proposal by the Program Committee obligates you to preregister (with appropriate fee) prior to June 1, 1991. If you fail to preregister, you will not be listed in the full program.

(2) Participants may appear on two (but no more than two) panels in any capacity-chairing a panel, acting as discussant or presenting a paper. This rule applies to APSA Program Committee panels or APSA Organized Section Panels, and Unaffiliated Group panels.

If you apply to several Program Committee Sections, please inform each section chairperson that yours is a multiple application. Also, in that case, please notify the other section chairpersons as soon as you have accepted an invitation for participation in another section. Proposals for papers should include author, title, and an abstract.

\section{Program Committee Sections}

Section leaders of the 1991 Program Committee will announce their proposed programs below.

\section{Political Thought and Philosophy: Historical Approaches. Fred Dallmayr, Department of Govern- ment, University of Notre Dame, Notre Dame, IN 46556; (219) 239-5491.}

Political theory or philosophy can boast a long and venerable tradition. However, the traditional "canon" has come under attack or scrutiny. What is the justification for the inclusion of "great books" in the canon? Should other texts be included? What do texts in the canon have to teach us today? Do they possess a particular relevance across time and especially for our time?

These questions are in the foreground of the 1991 panels. The point is not to rule out or neglect genuine historical analysis of any text in its historical context. However, some attention might be given to the question of the text's significance today and of its relation to the traditional canon. The desire is not to seek a shallow "relevance," but to induce reflection on what political thinking is all about, in light of experiences in our age and world.

Given the focus on contemporary significance, there are two themes 